\title{
The Genetic Structure of Australian Populations of Mycosphaerella musicola Suggests Restricted Gene Flow at the Continental Scale
}

\author{
H. L. Hayden, J. Carlier, and E. A. B. Aitken
}

First and third authors: Cooperative Research Centre for Tropical Plant Protection and Botany Department, University of Queensland, Brisbane, Queensland 4072, Australia; and second author: UMR 385 Biologie et Génétique des Interactions Plante-Parasite, CIRAD, TA 40/02, Avenue d'Agropolis, 34398, Montpellier, France.

Current address of H. L. Hayden: School of Botany, University of Melbourne, Melbourne, Victoria 3010 Australia. Accepted for publication 7 January 2005.

\begin{abstract}
Hayden, H. L., Carlier, J., and Aitken, E. A. B. 2005. The genetic structure of Australian populations of Mycosphaerella musicola suggests restricted gene flow at the continental scale. Phytopathology 95:489-498.

Mycosphaerella musicola causes Sigatoka disease of banana and is endemic to Australia. The population genetic structure of M. musicola in Australia was examined by applying single-copy restriction fragment length polymorphism probes to hierarchically sampled populations collected along the Australian east coast. The 363 isolates studied were from 16 plantations at 12 sites in four different regions, and comprised 11 populations. These populations displayed moderate levels of gene diversity $(H=0.142$ to 0.369$)$ and similar levels of genotypic richness and evenness. Populations were dominated by unique genotypes, but isolates sharing the same genotype (putative clones) were detected. Genotype
\end{abstract}

ABSTRACT

The ascomycete fungus Mycosphaerella musicola (anamorph = Pseudocercospora musae) causes (yellow) Sigatoka disease of banana (41). The disease results in necrotic leaf lesions which upon heavy infection reduce the photosynthetic capacity of the plant, and thus crop yield and fruit quality.

M. musicola is widely distributed within Australia, where banana production occurs over a wide range of climates, from the monsoonal tropics $\left(12^{\circ} \mathrm{S}\right.$ to $\left.18^{\circ} \mathrm{S}\right)$ to the subtropics $\left(26^{\circ} \mathrm{S}\right.$ to $30^{\circ} \mathrm{S}$ ). The major production areas are located in the wetsemitropics between Innisfail and Tully in North Queensland, and $1,000 \mathrm{~km}$ further south in the coastal subtropical regions of Bundaberg to Coolangatta (on the Queensland-New South Wales border) in Southeast Queensland, and Coolangatta to Macksville in Northern New South Wales (27). Different cultivars are also grown in each production region. Cavendish subgroup (AAA) varieties account for $95 \%$ of all cultivars grown in Australia, while the second commercially important cv. Lady Finger (AAB Pome subgroup) is cultivated primarily in Southeast Queensland and Northern New South Wales. Banana quarantine zones also exist within Queensland and New South Wales to control the movement of banana plants and fruit to reduce the risk of spread of pathogens such as Fusarium oxysporum f. sp. cubense, Banana bunchy top virus and quarantine pathogen M. fijiensis (black leaf streak disease), which does not occur on the Australian mainland.

Corresponding author: H. L. Hayden; E-mail address: hhayden@gmail.com

DOI: 10.1094/PHYTO-95-0489

(C) 2005 The American Phytopathological Society distribution was highly localized within each population, and the majority of putative clones were detected for isolates sampled from different sporodochia in the same lesion or different lesions on a plant. Multilocus gametic disequilibrium tests provided further evidence of a degree of clonality within the populations at the plant scale. A complex pattern of population differentiation was detected for M. musicola in Australia. Populations sampled from plantations outside the two major production areas were genetically very different to all other populations. Differentiation was much lower between populations of the two major production areas, despite their geographic separation of over $1,000 \mathrm{~km}$. These results suggest low gene flow at the continental scale due to limited spore dispersal and the movement of infected plant material.

Additional keywords: banana, population genetics, Sigatoka disease.
M. musicola is haploid and heterothallic (34); however, the production of pseudothecia and ascospores in vitro is difficult, and the mating-type idiomorphs (MAT-1 and MAT-2) at the MAT locus have not been characterized. Ascospores released from pseudothecia in infected plant tissue are carried by air currents over longer distances than conidia are dispersed (22). Ascospore production is strongly linked to "wet season" conditions of high rainfall and temperatures greater than $21^{\circ} \mathrm{C}$; thus, ascospores are only produced for short periods of the year $(35,36)$. Conidia are produced on a sporodochium and dispersed locally by rain and dew $(6,19,32)$. Conidial production occurs over a wide range of temperatures, provided rainwater or dew is present (32). On average, 50 conidia are produced per sporodochium (37), and successive batches can be produced (6); thus, conidia are the major source of inoculum when conditions are unsuitable for ascospore production.

A recent study of the global population structure of $M$. musicola revealed that the Australian population was most likely initiated by a founder event, separate from that which accompanied the establishment of the disease in the regions of Africa, Latin America, and the Caribbean (14). Unlike the related species $M$. fijiensis (30), the population structure of M. musicola has not been studied at a local or continental scale. M. musicola is endemic within Australia, where it was first reported in Queensland in 1924 and then spread throughout Australian plantations, reaching New South Wales in 1927 (31).

Interpretations of population structure are highly dependent upon the sampling scale used, the biology of the pathogen, and the history of its occurrence in an area. Studies of genetic structure have been conducted at a continental or regional scale for several other plant pathogens $(2-4,16,17,21,24,26,30)$. Low levels 
of population differentiation were reported among populations of M. graminicola from Oregon and California (3), Phaeosphaeria nodorum in Switzerland (16), and Sclerotinia sclerotiorum in Canada (17). In each of these studies different geographic populations had similar genetic structures and very low levels of population differentiation. The common explanation for this result was a high level of gene flow between the geographically separated populations. In contrast, high levels of population differentiation have been reported for other pathogens on the same geographic scale. For example, subpopulations of Cryphonectria parasitica in eastern North America had significantly different allele frequencies (24). It was hypothesized that random genetic drift and restricted gene flow had resulted in differentiation among these subpopulations of $C$. parasitica. In the case of $M$. fijiensis, high levels of genetic differentiation were detected at a continental scale in both Africa and the Latin America-Caribbean region (30). Genetic drift through bottlenecks or founder effects, accompanying the recent invasion of $M$. fijiensis in these regions, and also restricted gene flow through limited ascospore dispersal and/or the movement of infected plant material were proposed to explain the genetic differentiation observed.

Given the continuous distribution of banana along the east coast of Australia from North Queensland to Northern New South Wales $(2,000+\mathrm{km})$ in both commercial plantations and backyards, M. musicola may occur as one large population in Australia, with gene flow over long distances by airborne ascospores.

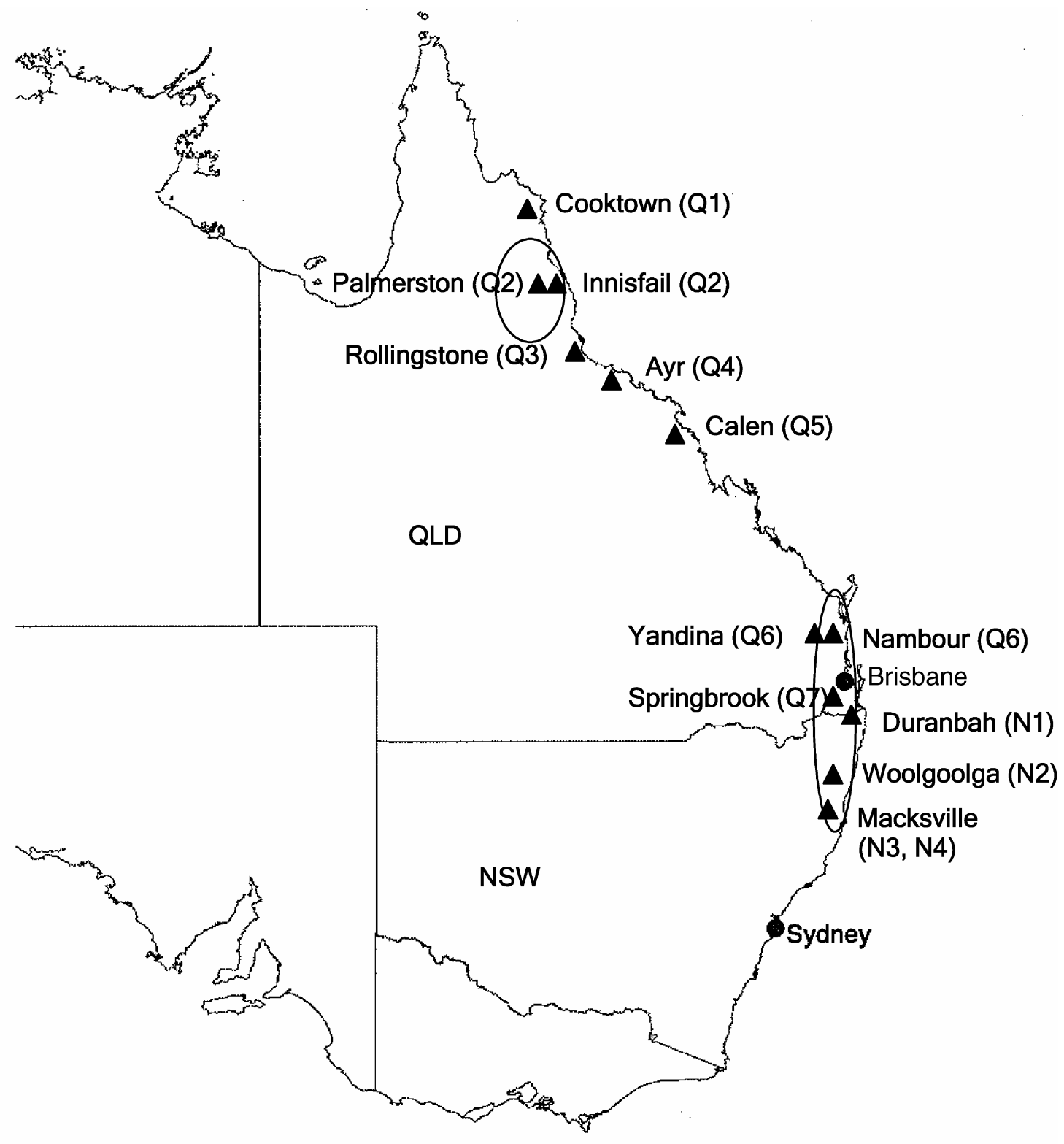

$\Delta$ Sampling site

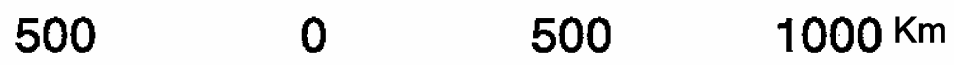

Fig. 1. The 11 populations of Mycosphaerella musicola (population code shown in parentheses) were collected from banana plantations in 12 locations throughout Queensland (QLD) and New South Wales (NSW), Australia, between March and July 1995. The two major banana production areas are circled on the map. 
Another issue that may affect population structure is host cultivar. In the southern regions, both 'Cavendish' and 'Lady Finger' bananas are cultivated and the presence of cultivar-specific populations in these regions requires examination. Information on the distribution of genetic diversity in M. musicola, recombination, and level of gene flow all have implications for disease management issues such as increased virulence and the development of fungicide resistance, and how these traits may spread among populations.

The objectives of this research were to infer the reproductive strategy and gene flow related to the dispersal processes of M. musicola, at a continental scale. Population genetic structure analysis was conducted using hierarchical samples from different locations in Australia and single-copy restriction fragment length polymorphism (RFLP) probes.

\section{MATERIALS AND METHODS}

Sampling. M. musicola isolates were collected from banana plantations along the Australian east coast in a hierarchical manner at five spatial scales: region, site, plants within a plantation, lesions on a plant, and sporodochia within a lesion. Isolates were collected from four regions (North Queensland, Central Queensland, Southeast Queensland, and New South Wales) at three different sites within each region (Fig. 1; Table 1) and one or two plantations per site. Distances between plantations ranged from 0.1 to $15 \mathrm{~km}$. Infected leaves were collected from between five and six plants selected at random within each plantation. A maximum of eight lesions were sampled per plant, and isolates were cultured from up to four different sporodochia within each lesion. Sampling was conducted between 6 March and 7 July 1995.

The sampling strategy was highly dependent upon disease incidence, severity, and the stage of lesion development. Samples were collected from commercial plantations where fungicide use was minimal, and from one plantation for sucker production. Where possible, plantations with both cvs. Cavendish and Lady Finger were sampled.

A total of 363 isolates of M. musicola collected from 16 plantations were examined. Populations were defined on a plantation basis. When adjacent plantations did not demonstrate population differentiation as estimated by the parameter $\theta$ (39) (data not shown), they were pooled into one population (Table 1). Seven populations from Queensland (Q populations) and four from New South Wales (N populations) were analyzed. The 11 populations studied, their sample size, and the hierarchical sampling details for region, site, and the number of plantations, plants, lesions, and sporodochia from which they originated are shown in Table 1.

Details of the isolation procedure from single sporodochia, production of hyphal tip cultures, and conditions for storage have been described previously (14). These isolates form part of the Cooperative Research Centre for Plant Protection (Brisbane, Australia) culture collection.
DNA extraction and Southern blot hybridization. Mycelium was grown in vitro in still culture and DNA was extracted as described previously (13). Thirteen single-copy RFLP probes from a genomic library of $M$. musicola (12) were used. The probes were Mm90-006, Mm90-007, Mm90-013, Mm90-015, Mm90-037, Mm90-044, Mm90-047, Mm90-063, Mm90-064, Mm90-080, Mm90-084, Mm90-090, and Mm90-108. Genomic DNA (5 $\mu \mathrm{g})$ from each of the 363 isolates was incubated in a total volume of $100 \mu \mathrm{l}$ at $37^{\circ} \mathrm{C}$ for $16 \mathrm{~h}$ with restriction enzymes HindIII and XhoI in separate reactions. The digest reaction was concentrated and fractionated by electrophoresis in a $0.8 \%$ agarose Tris-borateEDTA gel containing $1.5 \%$ ethidium bromide for $16 \mathrm{~h}$ at $30 \mathrm{~V}$ and transferred to Hybond N+ membranes (Amersham Pharmacia Biotech, Buckinghamshire, UK) by alkaline capillary blotting. Hybridization procedures were as previously described (13).

Data analysis. Each different probe $\times$ enzyme combination used was considered as an individual RFLP locus, and the different restriction fragments detected by each probe were treated as alleles. Allele frequencies were calculated at each RFLP locus for each population using the program BIOSYS-1 (38) (Laboratory of Molecular Systematics, Washington, DC). Nei's gene diversity $(H)(25)$ was calculated at each locus and then averaged over all loci for each population. Multilocus genotypes (MLG) were constructed for each isolate by compiling the alleles present at each RFLP locus for the estimation of genotypic diversity. Genotypic diversity $(G)$ was calculated for each population using the measure of Stoddart and Taylor (33). The rarefaction method was used to compare genotypic richness, which is the number of genotypes contained in a population, between populations of different sample sizes. Rarefaction curves yield the number of genotypes expected in a sample corresponding to the smallest sample size $(n)$ of all the populations being compared. The algorithm $<$ Rarefac.c $>$ (available from N. J. Grünwald, USDA-ARS Horticultural Crops Research Lab, Corvallis, OR) was used to calculate the number of expected genotypes, $E\left(g_{n}\right)$, for each population at a sample size of $n=1$ to $N$ (11). The evenness of distribution of genotypes within a population was determined by scaling $G$ by the number of genotypes observed $\left(g_{\text {obs }}\right)$ in a population as $G / g_{\text {obs }}$, allowing genotypic evenness to be compared between populations of different sample sizes (11). Estimates of genotypic diversity were compared for significant differences between populations using a $t$ test (8).

The contribution of sexual and asexual reproduction to the genetic structure of M. musicola in Australia was assessed by calculating the genotypic diversity (33) and gametic disequilibrium. The two tests of random association were conducted on populations containing all individuals at 15 loci and haplotype-corrected (HC) populations at 13 loci. Haplotype correction was done to eliminate artifactual associations among loci that result from sampling the same clone multiple times in a population. The loci 006XHO and 007-HIND were removed from the analyses to factor out any effect of physical linkage between locus pairs using the

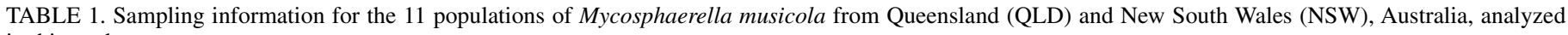
in this study

\begin{tabular}{|c|c|c|c|c|c|c|c|c|}
\hline Population & $\begin{array}{l}\text { Sample } \\
\text { size }\end{array}$ & Region & Site & $\begin{array}{c}\text { No. of } \\
\text { plantations }\end{array}$ & $\begin{array}{l}\text { No. of } \\
\text { plants }\end{array}$ & $\begin{array}{l}\text { No. of } \\
\text { lesions }\end{array}$ & $\begin{array}{c}\text { No. of } \\
\text { sporodochia }\end{array}$ & Host cultivar \\
\hline Q1 & 15 & North QLD & Cooktown & 1 & 4 & 10 & 15 & Cavendish \\
\hline Q2 & 27 & North QLD & Palmerston, Innisfail & 2 & 8 & 16 & 27 & Cavendish \\
\hline Q3 & 16 & Central QLD & Rollingstone & 1 & 6 & 10 & 16 & Cavendish \\
\hline Q4 & 32 & Central QLD & Ayr & 2 & 8 & 17 & 32 & Cavendish \\
\hline Q5 & 20 & Central QLD & Calen & 2 & 3 & 8 & 20 & Cavendish \\
\hline Q6 & 35 & Southeast QLD & Yandina, Nambour & 2 & 11 & 21 & 35 & Cavendish, Lady Finger \\
\hline Q7 & 16 & Southeast QLD & Springbrook & 1 & 5 & 15 & 16 & Cavendish, Lady Finger \\
\hline N1 & 45 & NSW & Duranbah & 2 & 8 & 28 & 45 & Cavendish, Lady Finger \\
\hline N2 & 62 & NSW & Woolgoolga & 1 & 9 & 40 & 62 & Cavendish, Lady Finger \\
\hline N3 & 48 & NSW & Macksville & 1 & 4 & 22 & 48 & Cavendish \\
\hline N4 & 47 & NSW & Macksville & 1 & 4 & 21 & 47 & Cavendish \\
\hline Total & 363 & & & 16 & 70 & 208 & 363 & \\
\hline
\end{tabular}


same probe (Mm90-006, Mm90-007) on multilocus disequilibrium. First, a Fisher exact test was used to test for departure from gametic equilibrium using the program GENEPOP (version 3.1b; Centre d'Ecologie Fonctionnelle et Evolutive, Centre National de la Recherche Scientifique, Montpellier, France). Contingency ta- bles were created for all possible pairs of polymorphic loci in each population and analyzed with a Markov chain method (parameters set to 1,000 dememorizations and 1,000 iterations per batch for 100 batches) to estimate the exact probability (28). Locus pairs were considered to be in gametic disequilibrium if the

TABLE 2. Allele frequencies for the 11 Australian populations of Mycosphaerella musicola at 15 restriction fragment length polymorphism loci

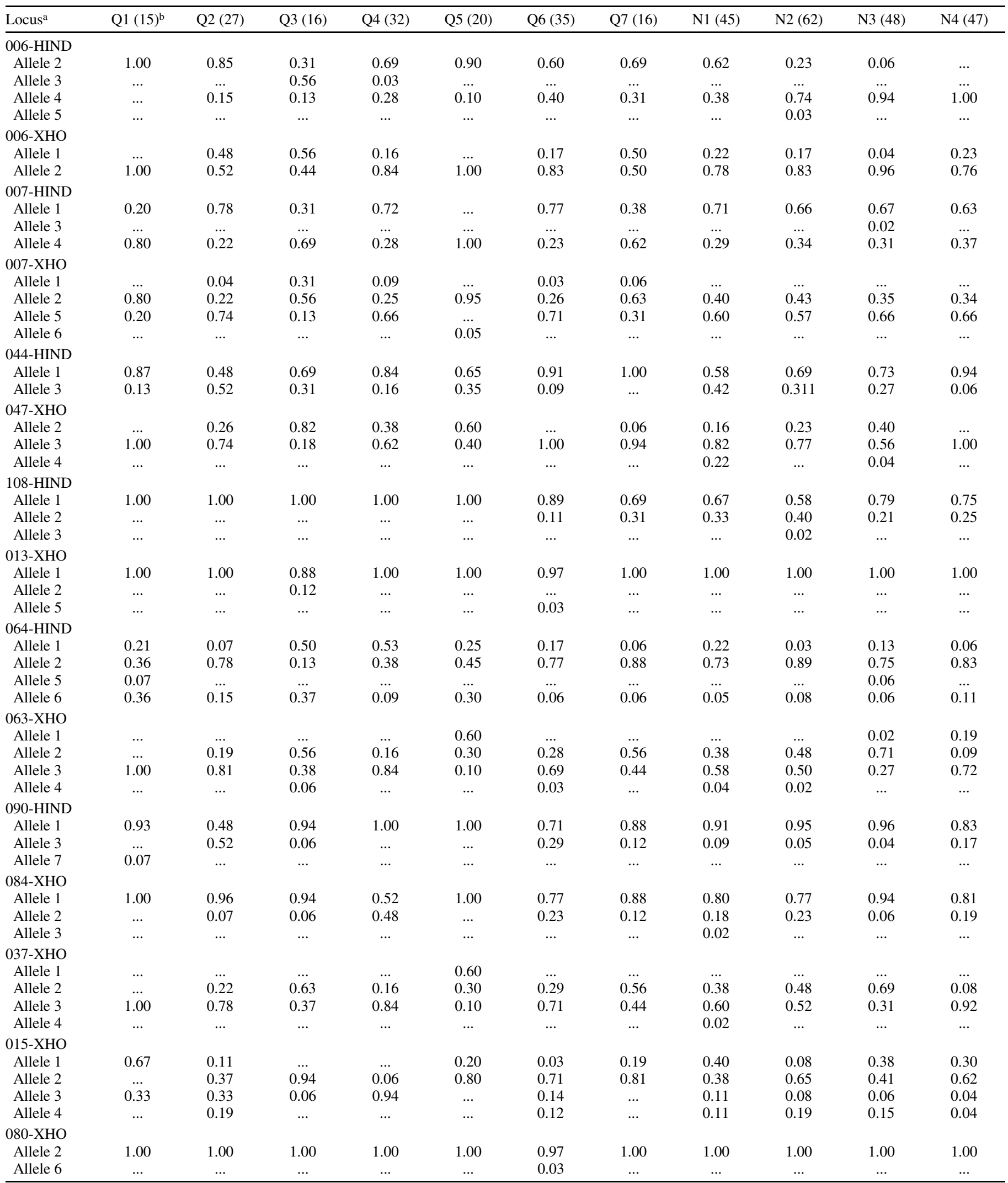

${ }^{a}$ Frequencies are shown only for alleles present at each locus for the Australian M. musicola populations.

b Population sample size. 
exact probability was less than 0.05 . The sequential Bonferroni test (15) was applied to determine "table-wide" 5\% significance levels (29). Second, multilocus gametic disequilibrium was tested using the index of multilocus gametic disequilibrium, $\bar{r}_{d}$ (1), which is a modification of the index of association, $I_{A}(5)$, as implemented in the program MULTILOCUS (version Win 1.3b; Department of Biology, Imperial College, Silwood Park, UK). The index $\bar{r}_{d}$ has an expected value of zero if there is no association of alleles at unlinked loci, as expected in a randomly mating population. The significance of $\bar{r}_{d}$ was tested by comparing the observed variance with the distribution of the variance expected under the null hypothesis of random mating, as determined from 1,000 randomizations of the haplotype data.

Genetic differentiation between population pairs was estimated using $\hat{\theta}$ (39), an unbiased estimator of the parameter $F_{S T}(40)$. The program GENEPOP was used to estimate $\hat{\theta}$ by a weighted analysis of variance. To test genetic differentiation, an exact test for differences in allele frequencies was performed for each locus and multilocus statistics were obtained using Fisher's combined probability test (28). The significance levels were adjusted subsequently using the sequential Bonferroni correction method (29). Bootstrap 95\% confidence intervals for the $F_{S T}$ estimates were obtained over loci using the program FSTAT (DOS version 1.2; Department of Ecology and Evolution, Faculty of Biology and Medicine, University of Lausanne, Switzerland).

An unrooted neighbor-joining cluster analysis was performed with chord distance $\left(D_{C}\right)(7)$ using the program POPULATIONS (version 1.2.28; Laboratoire Populations, Génétique et Evolution, Centre National de la Recherche Scientifique, Gif-sur-Yvette, France) and visualized using the program TREEVIEW (version 1.6.6; Institute of Biomedical and Life Sciences, University of Glasgow, UK). The resulting tree was bootstrapped among loci (1,000 permutations).

\section{RESULTS}

Genetic diversity within populations. A total of 48 alleles was found at the 15 RFLP loci. The 11 Australian populations of M. musicola contained similar alleles, although frequencies differed at many loci between the populations from major production areas (Q2, Q6, Q7, N1, N2, N3, and N4) and those from plantations outside these regions (Q1, Q3, Q4, and Q5) (Table 2). The lowest genetic diversity was observed in populations Q1 and Q5. Gene diversity (25) was moderate for the 11 populations and ranged from $H=0.14$ to 0.37 (Table 3 ).

One hundred and ninety-five different genotypes of $\mathrm{M}$. musicola were found among 363 isolates in the 11 Australian populations examined. Genotypic diversity for the total population was thus at $54 \%$ of the possible maximum, where every isolate has a unique genotype. One hundred and four genotypes were observed only once in the total population, while the most frequent genotype was present eight times. Populations generally consisted of $50 \%$ unique genotypes (represented by one isolate), with the remaining genotypes having a frequency of two to four within the sample. Genotypes with a frequency greater than one accounted for $91(47 \%)$ of the 195 genotypes detected and represented 259 of the 363 isolates studied. An examination of the spatial distribution pattern of the frequent genotypes within each population revealed a highly localized distribution. Of the frequent genotypes, $57(62 \%)$ were detected for isolates sampled from different sporodochia within the same lesion, representing 146 isolates: $16(18 \%)$ for 45 isolates that were sampled from different lesions on the same plant; $8(9 \%)$ for 25 isolates that were sampled from different plants in a plantation or plantations of the same population; and $10(11 \%)$ for 43 isolates that were sampled from different sites, and thus occurring in different populations (Table 4). Genotypes identified as being widespread over several sites were generally found in different populations within the same region (Table 4).

Genotypic diversity (33) for the populations ranged from $G=$ 5.814 to 26.316 (Table 3). Genotypic richness estimates by rarefaction were very close to the observed number of genotypes for each population. Genotypic richness $E\left(g_{n}\right)$, as estimated by the smallest sample size $(n=15)$, was lowest in populations Q3 (6.875), Q1 (8.620), and Q5 (8.403), while all other populations were within the range of 9.767 to 12.973 (Table 3). Genotypic evenness $\left(G / g_{\text {obs }}\right)$ estimates were high for 10 of the 11 populations, ranging from 0.712 to 0.889 , with the exception of population Q4 with a moderate evenness estimate of 0.553 (Table 3). The lower evenness estimate observed in population Q4 can be explained by the domination MLG 101, which was detected eight times among the 32 individuals in the population (Table 4). Significant differences in genotypic diversity were detected between several population pairs using a $t$ test (8). The significantly different population pairs were Q2 and Q4, Q3 and N1, Q4 and Q7, and Q4 and N1.

Gametic disequilibrium. Gametic disequilibrium was tested for the whole data set at 15 loci, and the HC data set at 13 loci. The two tests for linkage within the 11 Australian populations of M. musicola revealed very different outcomes. The Fisher exact test detected low levels of disequilibrium for the 11 populations in the locus-by-locus comparisons (Table 5). Upon haplotype correction and removal of two loci that may have contributed to linkage (006-XHO and 007-HIND), 5 of the 11 populations exhibited no departures from gametic equilibrium after the Bonferroni correction was applied (15), while low levels (2\% or less) of gametic disequilibrium were detected for the remaining six populations. The more powerful test of the index of multilocus gametic disequilibrium, $\bar{r}_{d}$, which compares all loci together at the same time, revealed that $\bar{r}_{d}$ differed significantly from zero for all 11

TABLE 3. Genetic diversity parameters for the 11 Australian populations of Mycosphaerella musicola examined at 15 loci

\begin{tabular}{|c|c|c|c|c|c|c|c|}
\hline Population & $\begin{array}{c}\text { Sample size } \\
n\end{array}$ & $\begin{array}{c}\text { Gene diversity } \\
(H)^{\mathrm{a}}\end{array}$ & $\begin{array}{c}\text { Genotypes observed } \\
g_{\text {obs }}\end{array}$ & $\begin{array}{c}\text { Genotypic richness }{ }^{\mathrm{b}} \\
E\left(g_{n}\right)\end{array}$ & $\begin{array}{c}E\left(g_{n}\right) \text { for smallest } n^{\mathrm{c}} \\
(n=15)\end{array}$ & $\begin{array}{l}\text { Genotypic diversity } \\
\qquad(G)^{\mathrm{d}}\end{array}$ & $\begin{array}{c}\text { Genotypic evenness } \\
\left(G / g_{\text {obs }}\right)\end{array}$ \\
\hline Q1 & 15 & 0.142 & 9 & 8.620 & 8.620 & 6.410 & 0.712 \\
\hline Q2 & 27 & 0.311 & 18 & 17.567 & 11.690 & 13.889 & 0.772 \\
\hline Q3 & 16 & 0.331 & 7 & 6.875 & 6.875 & 5.814 & 0.831 \\
\hline Q4 & 32 & 0.271 & 16 & 15.724 & 9.767 & 8.850 & 0.553 \\
\hline Q5 & 20 & 0.217 & 9 & 8.897 & 8.403 & 8.000 & 0.889 \\
\hline Q6 & 35 & 0.297 & 19 & 18.739 & 11.226 & 14.706 & 0.774 \\
\hline Q7 & 16 & 0.294 & 11 & 10.578 & 10.578 & 9.174 & 0.834 \\
\hline N1 & 45 & 0.369 & 31 & 30.530 & 12.973 & 24.390 & 0.787 \\
\hline $\mathrm{N} 2$ & 62 & 0.341 & 35 & 33.692 & 12.493 & 26.316 & 0.752 \\
\hline N3 & 48 & 0.299 & 25 & 24.788 & 12.046 & 19.608 & 0.784 \\
\hline N4 & 47 & 0.251 & 27 & 26.699 & 12.313 & 21.739 & 0.805 \\
\hline
\end{tabular}

a Nei's genetic diversity (25).

${ }^{\mathrm{b}} E\left(g_{n}\right)$ is the number of expected genotypes at a sample size of $n=1$ to $N(11)$ as calculated by the algorithm $<$ Rarefac.c $>$.

${ }^{c} E\left(g_{n}\right)$ is compared for each population at the smallest population size $(n=15)$ as determined by population Q1.

d Stoddart and Taylor's genotypic diversity (33). 
populations and ranged from 0.049 for population Q6 to 0.219 for population Q3. When the HC populations were examined at 13 loci, 7 of the 11 populations demonstrated low yet significant gametic disequilibrium at $P<0.05$ (Q3 HC, Q4 HC, Q5 HC, Q7 $\mathrm{HC}, \mathrm{N} 1 \mathrm{HC}, \mathrm{N} 3 \mathrm{HC}$, and $\mathrm{N} 4 \mathrm{HC}$ ), while 4 of the 11 populations differed significantly from zero at $P<0.01(\mathrm{Q} 3 \mathrm{HC}, \mathrm{N} 1 \mathrm{HC}, \mathrm{N} 3$ $\mathrm{HC}$, and N4 HC) (Table 5).

Genetic differentiation among populations. Genetic differentiation was estimated among the 11 populations of $M$. musicola using the parameter $F_{S T}$ (Table 6). The $F_{S T}$ values between all population pairs were significant at the table-wide 5\% level (29) (Table 6). The lowest $F_{S T}$ value was 0.04 , between the neighboring populations $\mathrm{N} 1$ and $\mathrm{N} 2$. In contrast, the highest $F_{S T}$ value was 0.45 , between populations Q5 and N4. The $F_{S T}$ value for the two most geographically distant populations Q1 and N4 was 0.36 .

Low to moderate levels of population differentiation were observed between populations within the southern production area (Q6, Q7, N1, N2, N3, and N4). In nearest-neighbor comparisons between these populations, $F_{S T}$ values ranged from 0.04 (N1 to $\mathrm{N} 2$ ) to 0.18 (N4 to N5). The population Q2, located in the North Queensland production area, was found to be most similar to two populations in the southern production area, Q6 $\left(F_{S T}=0.09\right)$ and $\mathrm{N} 1\left(F_{S T}=0.08\right)($ Table 6$)$. This equates to less than $10 \%$ genetic differentiation between these populations. In contrast, high levels of genetic differentiation were observed for populations from outside the major production areas: Q1, Q3, Q4, and Q5. The Q3 and Q5 populations showed higher levels of differentiation when com- pared with neighboring population Q4 $\left(F_{S T}=0.33\right.$ and 0.43 , respectively) than with each other $\left(F_{S T}=0.24\right)$ (Table 6).

Examination of the confidence intervals of the $F$ statistics for population pairs indicated a significant difference $(P<0.05)$ existed between some of the populations pairs (Fig. 2). While population pairs from the southern region, such as N4-N2, N3N2, N2-N1, N1-Q7, and N1-Q6, did not differ significantly from each other, they were each significantly different from population pairs from the northern region, such as Q2-Q1, Q3-Q1, Q3-Q2, Q5-Q2, Q4-Q3, and Q5-Q4 (Fig. 2). The patterns of genetic differentiation observed between the 11 populations of $\mathrm{M}$. musicola with the parameter $F_{S T}$ are further supported by the unrooted neighbor-joining tree based on $D_{C}$ (7) (Fig. 3).

A preliminary examination of population differentiation on the basis of host cultivar was tested with isolates collected from Cavendish $(n=28)$ and Lady Finger $(n=33)$ banana plants grown on adjacent blocks in the same plantation (population N2). Genetic differentiation tests revealed significant differences $(P<$ 0.05 ) in allele frequencies at 6 out of 13 loci between the Cavendish and Lady Finger populations; however, only a very low level of differentiation was observed with the parameter $F_{S T}$ for this population pair $\left(F_{S T}=0.037\right)$.

\section{DISCUSSION}

Hierarchical sampling revealed that genetic diversity was distributed on a fine scale within all Australian populations of

TABLE 4. Occurrence of multilocus genotypes (MLG) among populations of Mycosphaerella musicola sampled in Australia

\begin{tabular}{|c|c|c|c|c|c|c|c|c|c|c|c|c|c|}
\hline \multirow[b]{2}{*}{ Location } & \multirow[b]{2}{*}{$\mathrm{MLG}^{\mathrm{a}}$} & \multicolumn{11}{|c|}{ Population $^{\mathrm{b}}$} & \multirow[b]{2}{*}{ Total } \\
\hline & & Q1 & Q2 & Q3 & Q4 & Q5 & Q6 & Q7 & N1 & $\mathrm{N} 2$ & N3 & N4 & \\
\hline \multirow{17}{*}{$\begin{array}{l}\text { Different lesion } \\
\text { same plant }\end{array}$} & & & & & & & & & & & & & \\
\hline & 4 & 4 & $\bullet$ & $\bullet$ & • & • & $\bullet$ & $\bullet$ & $\bullet$ & $\bullet$ & • & $\bullet$ & 4 \\
\hline & 14 & • & $\bullet$ & • & • & $\bullet$ & • & 2 & • & $\bullet$ & • & $\bullet$ & 2 \\
\hline & 21 & • & $\bullet$ & $\bullet$ & $\bullet$ & $\bullet$ & • & $\bullet$ & 3 & $\bullet$ & • & $\bullet$ & 3 \\
\hline & 25 & • & $\bullet$ & • & 2 & • & • & $\bullet$ & • & $\bullet$ & • & • & 2 \\
\hline & 78 & • & $\bullet$ & • & • & • & 2 & $\bullet$ & $\bullet$ & $\bullet$ & • & $\bullet$ & 2 \\
\hline & 93 & • & $\bullet$ & $\bullet$ & $\bullet$ & • & • & $\bullet$ & $\bullet$ & 2 & • & $\bullet$ & 2 \\
\hline & 101 & • & $\bullet$ & $\bullet$ & 8 & • & $\bullet$ & $\bullet$ & $\bullet$ & $\bullet$ & - & $\bullet$ & 8 \\
\hline & 103 & • & $\bullet$ & $\bullet$ & 2 & • & $\bullet$ & $\bullet$ & $\bullet$ & $\bullet$ & $\bullet$ & $\bullet$ & 2 \\
\hline & 113 & • & 2 & $\bullet$ & • & $\bullet$ & • & $\bullet$ & $\bullet$ & $\bullet$ & • & $\bullet$ & 2 \\
\hline & 123 & • & $\bullet$ & $\bullet$ & • & • & • & $\bullet$ & $\bullet$ & $\bullet$ & • & 3 & 3 \\
\hline & 134 & • & $\bullet$ & $\bullet$ & • & $\bullet$ & • & 2 & $\bullet$ & $\bullet$ & • & $\bullet$ & 2 \\
\hline & 144 & • & $\bullet$ & $\bullet$ & • & • & • & 3 & $\bullet$ & $\bullet$ & • & $\bullet$ & 3 \\
\hline & 146 & - & $\bullet$ & $\bullet$ & $\bullet$ & • & $\bullet$ & $\bullet$ & $\bullet$ & 4 & • & $\bullet$ & 4 \\
\hline & 153 & $\bullet$ & $\bullet$ & • & $\bullet$ & • & • & $\bullet$ & $\bullet$ & 2 & • & • & 2 \\
\hline & 174 & $\bullet$ & $\bullet$ & • & $\bullet$ & • & • & $\bullet$ & $\bullet$ & 2 & • & • & 2 \\
\hline & 191 & • & $\bullet$ & 2 & $\bullet$ & • & • & $\bullet$ & $\bullet$ & $\bullet$ & • & $\bullet$ & 2 \\
\hline \multicolumn{14}{|c|}{ Different plants, same } \\
\hline \multirow[t]{8}{*}{ plantation } & 8 & 2 & $\bullet$ & $\bullet$ & $\bullet$ & $\bullet$ & $\bullet$ & $\bullet$ & $\bullet$ & $\bullet$ & $\bullet$ & $\bullet$ & 2 \\
\hline & 28 & $\bullet$ & $\bullet$ & $\bullet$ & $\bullet$ & $\bullet$ & $\bullet$ & $\bullet$ & $\bullet$ & 4 & $\bullet$ & • & 4 \\
\hline & 55 & • & $\bullet$ & 4 & $\bullet$ & $\bullet$ & $\bullet$ & $\bullet$ & $\bullet$ & $\bullet$ & • & $\bullet$ & 4 \\
\hline & 58 & - & $\bullet$ & 2 & • & • & • & $\bullet$ & $\bullet$ & $\bullet$ & • & $\bullet$ & 2 \\
\hline & 70 & • & $\bullet$ & $\bullet$ & • & - & • & $\bullet$ & 4 & $\bullet$ & • & • & 4 \\
\hline & 156 & • & $\bullet$ & $\bullet$ & • & - & 2 & $\bullet$ & - & $\bullet$ & • & $\bullet$ & 2 \\
\hline & 158 & - & $\bullet$ & $\bullet$ & • & $\bullet$ & $\bullet$ & $\bullet$ & $\bullet$ & $\bullet$ & 2 & $\bullet$ & 2 \\
\hline & 164 & - & $\bullet$ & • & • & - & $\bullet$ & $\bullet$ & - & $\bullet$ & 5 & $\bullet$ & 5 \\
\hline \multirow[t]{10}{*}{ Different sites } & 40 & - & $\bullet$ & $\bullet$ & - & • & • & $\bullet$ & 1 & $\bullet$ & 1 & $\bullet$ & 2 \\
\hline & 69 & • & 1 & $\bullet$ & $\bullet$ & • & $\bullet$ & $\bullet$ & 1 & $\bullet$ & • & $\bullet$ & 2 \\
\hline & 71 & - & $\bullet$ & $\bullet$ & 2 & $\bullet$ & 4 & $\bullet$ & • & $\bullet$ & • & • & 6 \\
\hline & 79 & • & • & • & • & • & • & 2 & 2 & $\bullet$ & • & • & 4 \\
\hline & 83 & • & • & • & • & • & 4 & $\bullet$ & • & 2 & • & 2 & 8 \\
\hline & 87 & • & • & • & • & • & 2 & • & • & 1 & • & $\bullet$ & 3 \\
\hline & 136 & • & • & • & • & • & • & 1 & • & 3 & • & • & 4 \\
\hline & 145 & • & • & • & • & • & • & 1 & • & • & 2 & $\bullet$ & 3 \\
\hline & 157 & • & • & • & • & • & 2 & • & 2 & 3 & • & $\bullet$ & 7 \\
\hline & 189 & • & • & 3 & 1 & • & • & $\bullet$ & • & $\bullet$ & • & $\bullet$ & 4 \\
\hline $\mathrm{N}^{\mathrm{c}}$ & & 15 & 27 & 16 & 32 & 20 & 35 & 16 & 45 & 62 & 48 & 47 & 113 \\
\hline
\end{tabular}

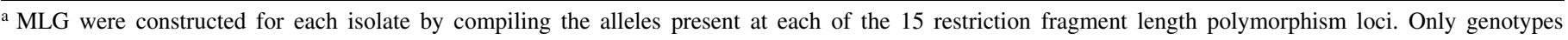
occurring more than once in the population and not from the same lesion were included.

b Number of isolates within the population with the specified MLG.

c Total number of isolates analyzed in each population. 
M. musicola. Each population contained many different genotypes with a highly localized distribution. The finest spatial scale investigated was sporodochia within a single lesion. In most cases different sporodochia taken from the same lesion had the same genotype, indicating that each lesion was the product of infection by one spore. At the plant scale, the majority of lesions corresponded to a unique genotype, most likely produced by independent infection events. A similar observation was made for the related species $M$. graminicola on wheat (20), where $75 \%$ of the lesions examined corresponded to a unique genotype. Lesions on a plant could therefore be considered the smallest unit of genetic diversity in the Australian populations of M. musicola.

There is a strong contrast between the moderate level of genotypic diversity detected in populations and the high number of unique genotypes observed in each population compared with the number of lesions sampled. This result may be explained by sexual and asexual reproduction in M. musicola (18), combined with the sampling scheme. While sexual reproduction creates new genotypes through recombination, the detection of putative clones recovered from different lesions on the same plant supports the evidence of splash dispersal by conidia, and indicates that dispersal is closely restricted to the same plant or nearby plants. The hierarchical sampling scheme of isolating several sporodochia within each lesion repeatedly sampled the same genotype, which in turn reduced the richness component of the genotypic diversity of the populations of $M$. musicola. In addition, because there were differences in the number of sporodochia isolated per lesion among the populations, the probability of recovering clones is different for the various populations effecting comparisons of genotypic diversity. Using isolates derived from asexual spores and a small number of plants per plantation, our research has provided new information on the importance of asexual reproduction in the population structure of $M$. musicola at the plant scale. Future population studies of $M$. musicola may benefit from adopting a sampling strategy of one isolate per lesion, and sampling more lesions per plant.

Despite very small population sample sizes for testing of the null hypothesis of random mating, significant gametic disequilibrium was detected in more than half the HC populations using the index of association test. Large population sizes are needed to reject the null hypothesis of random mating when using Fisher's exact test, though $\bar{r}_{d}$ is less sensitive to population size (23). While $\bar{r}_{d}$ was close to zero and thus weak gametic disequilibrium in the $\mathrm{HC}$ populations, significance testing based on resampling did not

TABLE 5. Gametic disequilibrium calculated for all possible loci pairs for each Australian population of Mycosphaerella musicola using 15 restriction fragment length polymorphism (RFLP) loci, and for haplotype-corrected (HC) populations using 13 RFLP loci

\begin{tabular}{|c|c|c|c|c|c|}
\hline Population & $N$ & $\begin{array}{c}\text { Loci pairs at significant } \\
\text { disequilibrium }^{\mathrm{a}}\end{array}$ & $\begin{array}{c}\text { Significant loci after } \\
\text { Bonferroni correction }\end{array}$ & $\bar{r}_{d}^{\mathrm{c}}$ & $P$ value \\
\hline$\overline{\mathrm{Q} 1}$ & 15 & $1 / 15$ & $1 / 15$ & 0.121 & 0.010 \\
\hline Q2 & 27 & $9 / 66$ & $2 / 66$ & 0.059 & $<0.001$ \\
\hline Q4 & 32 & $18 / 55$ & $13 / 55$ & 0.137 & $<0.001$ \\
\hline Q5 & 20 & $6 / 28$ & $6 / 28$ & 0.153 & $<0.001$ \\
\hline Q6 & 35 & $14 / 91$ & $3 / 91$ & 0.049 & $<0.001$ \\
\hline Q7 & 16 & $3 / 66$ & $2 / 66$ & 0.072 & $<0.001$ \\
\hline N3 & 48 & $23 / 78$ & $2 / 78$ & 0.063 & $<0.001$ \\
\hline N4 & 47 & $10 / 55$ & $3 / 55$ & 0.062 & $<0.001$ \\
\hline $\mathrm{Q} 1 \mathrm{HC}^{\mathrm{d}}$ & 9 & $0 / 10$ & 0 & 0.068 & 0.113 \\
\hline $\mathrm{Q} 2 \mathrm{HC}$ & 18 & $1 / 45$ & 0 & 0.018 & 0.133 \\
\hline Q3 HC & 7 & $1 / 55$ & 0 & 0.131 & 0.003 \\
\hline Q4 HC & 16 & $1 / 35$ & 0 & 0.047 & 0.015 \\
\hline Q5 HC & 9 & $2 / 28$ & $1 / 28$ & 0.094 & 0.016 \\
\hline $\mathrm{N} 4 \mathrm{HC}$ & 27 & $4 / 36$ & $1 / 36$ & 0.060 & 0.004 \\
\hline
\end{tabular}

a Significance level of $P<0.05$ for exact tests. Values indicate the number of loci pairs at significant disequilibrium.

b Table-wide 5\% significant level.

c $\bar{r}_{d}$ is the index of multilocus gametic disequilibrium (1).

${ }^{\mathrm{d}}$ Loci 006-XHO and 007-HIND were not included in the analyses at 13 loci to factor out any effect of linkage between locus pairs using the same probe (Mm90006, Mm90-007) on multilocus disequilibrium.

TABLE 6. Mean $F_{S T}(\theta)$ estimates based upon 15 restriction fragment length polymorphism loci for all population pairs of Mycosphaerella musicola sampled within Australia

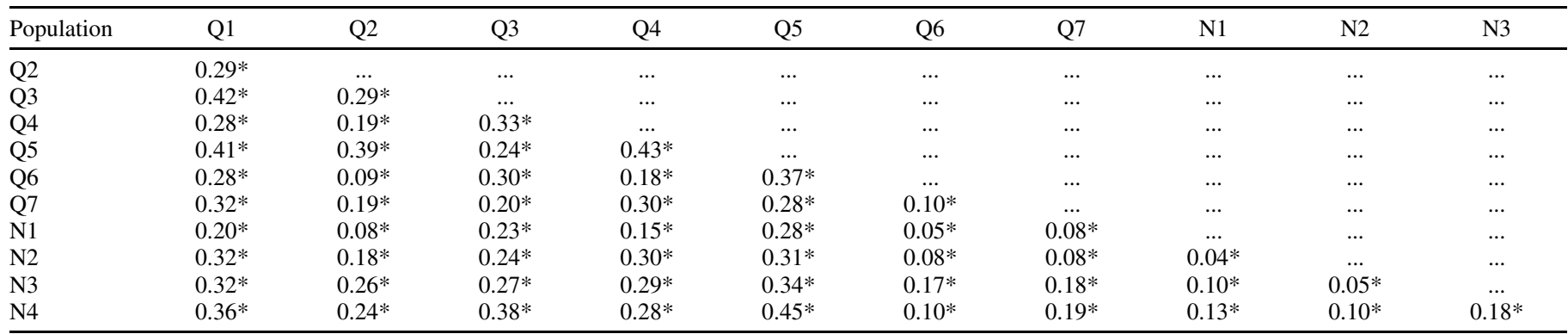

a * Indicates significant genetic differentiation at the "table-wide" 5\% level (29) using Fisher's combined probability test (28). $\hat{\theta}$ (39) is an unbiased estimator of the parameter $F_{S T}(40)$. 
support the null hypothesis of random mating. These results can be contrasted with previous studies of $M$. fijiensis, using single ascospore-derived isolates (30) and a mixture of single ascospore and conidial-derived isolates (13) which showed random mating in populations of $M$. fijiensis at plant and plantation scales. However, a significant difference exists between the epidemiology of $M$. fijiensis and $M$. musicola, in that the primary inoculum of M. fijiensis is ascospores, with conidia produced at much lower numbers and playing a minor role in disease spread $(9,10)$. Our results indicate that while pseudothecia of M. musicola can be observed in banana plantations, the prevalence of asexual reproduction may outweigh the effects of sexual reproduction on the genetic structure of M. musicola in Australia.

One of the most significant findings of this study was the high degree of population differentiation between populations from different regions and sites over a sampling transect of greater than $1,800 \mathrm{~km}$. No differentiation between populations had been predicted on the basis of host distribution and ascospore production by $M$. musicola. Banana occurs in plantations and as common backyard plants along much of the Australian east coast, providing a corridor for gene flow by airborne ascospores of $\mathrm{M}$. musicola. The results of this study did not support the hypothesis of large-scale migration between populations by airborne spores. The hierarchical sampling scheme revealed a complex pattern of population differentiation between sites and regions. Between the different sampling sites, there was a high degree of genetic differentiation among the northern populations (Q1, Q2, Q3, Q4, and Q5) and low to moderate differentiation among the southern populations (Q6, Q7, N1, N2, N3, and N4). $F_{S T}$ estimations showed that populations from the major production areas (Q2, Q6, Q7, N1, N2, N3, and N4) were more closely related to each other than to the isolated populations outside the production areas (Q1, Q3, Q4, and Q5). Significance testing of the $F_{S T}$ estimates confirmed difference between population pairs from the northern region compared with population pairs from the southern region.
A high level of genetic differentiation was observed when the North Queensland population Q1 and the Central Queensland populations Q3, Q4, and Q5 were compared with each other and compared with populations from the major production areas. This

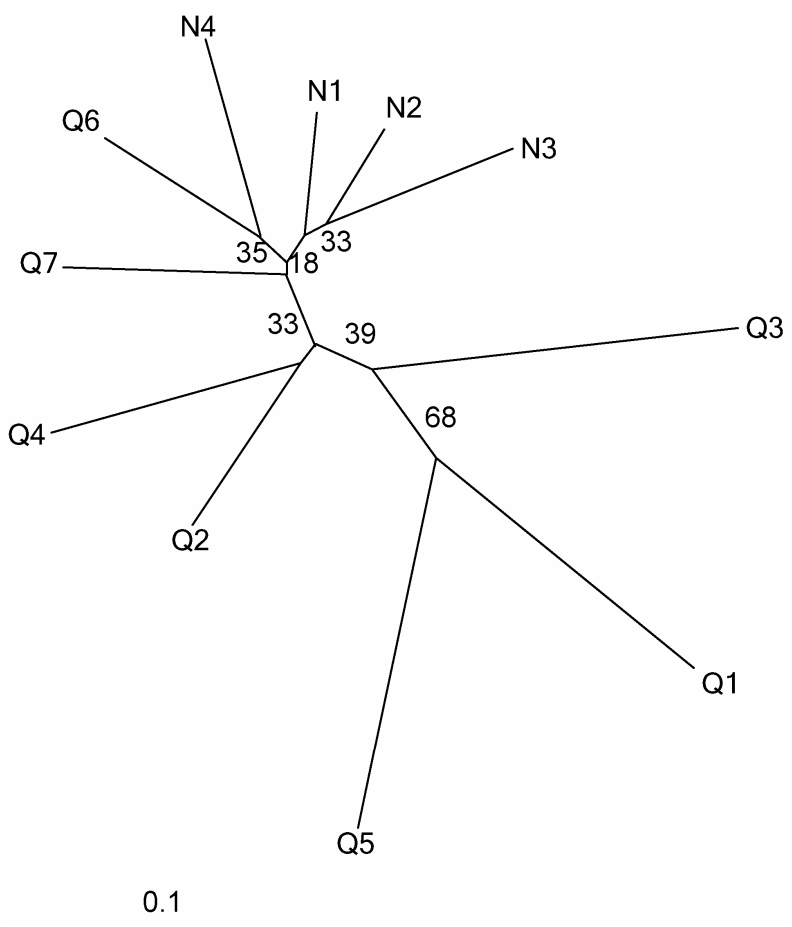

Fig. 3. Genetic differentiation between 11 populations of Mycosphaerella musicola from Australia. Unrooted neighbor-joining tree based on the chord distance (7). The data were bootstrapped 1,000 times over each locus. Table 1 provides a key for population codes.

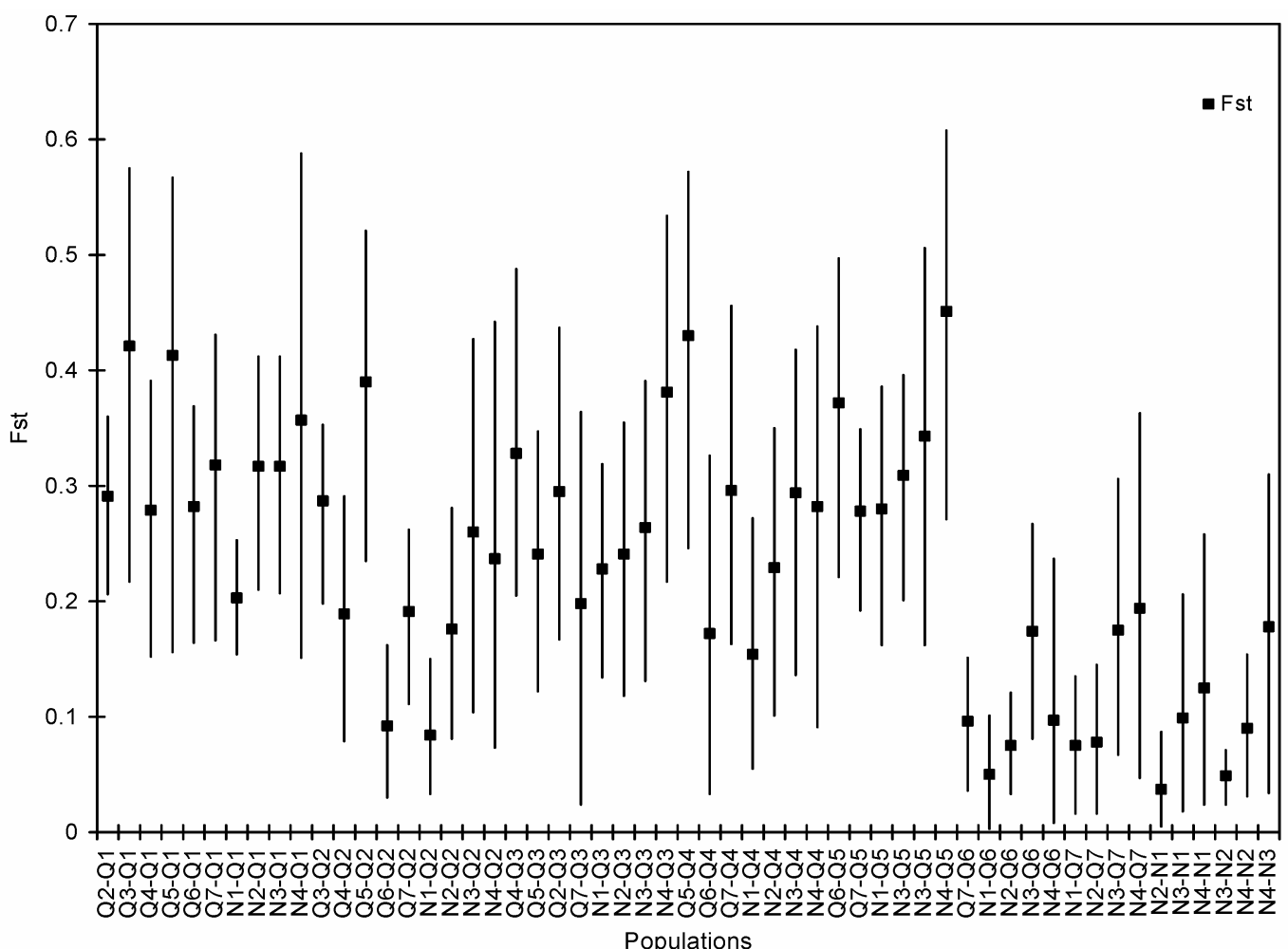

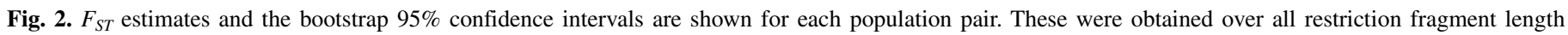

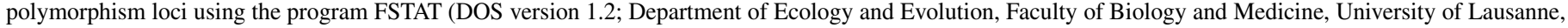

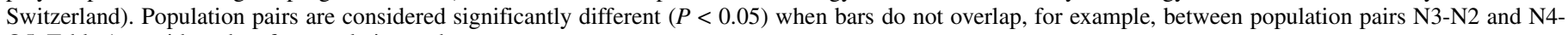
Q5. Table 1 provides a key for population codes. 
differentiation may have been produced by geographical isolation, resulting in limited gene flow between the plantations. These populations were sampled from small plantations outside of the highly localized northern production area (between Innisfail and Tully) and long distances (often in excess of $50 \mathrm{~km}$ ) from any other plantations. Airborne spore dispersal may have been ineffective over these large distances, particularly if the host target area is very small. In the absence of gene flow, random genetic drift will cause isolated small populations to develop different allele frequencies at neutral loci, creating divergence between populations. This effect can be seen clearly at several loci for the isolated population $\mathrm{Q} 4$, when compared with neighboring populations Q3 and Q5 (Table 2).

Populations in the southern production area (Q6, Q7, N1, N2, $\mathrm{N} 3$, and N4) were characterized by low to moderate population differentiation, indicating gene flow may be more frequent in this region, either by conidia or ascospores over long distances. The southern banana production region extends over several hundred kilometers from Bundaberg north of Brisbane to Macksville (Fig. 1). This would account for the genetic similarity and shared genotypes between adjacent plantations at a site and sites within a region in the southern production area. Seven of the ten genotypes spread over more than one site were identified in populations in the southern production area (Table 4).

It is very difficult to apply the hypothesis of gene flow by spore dispersal to explain the low level of population differentiation between the geographically separated Q2 and N1 populations $\left(F_{S T}=\right.$ 0.08). The effective dispersal range of $M$. musicola ascospores is undetermined (22); however, long-range ascospore dispersal between the northern and southern production areas (where Q2 and $\mathrm{N} 1$ are situated) is highly unlikely given the high level of population differentiation observed for populations Q3, Q4, and Q5, located in the path between the two areas. It is thus proposed that historical gene flow is responsible for the genetic similarity of the populations of the northern and southern production areas. An alternative mechanism for gene flow may be the movement of infected plant material. Commercial banana plantings commenced in Australia around 1870, just north of Brisbane. During the early 1900s, the major production areas were located in North Queensland, while after World War I, production shifted south to Southeast Queensland and Northern New South Wales (27). Infected plant material could have been transferred between the two regions during the establishment of plantations. The movement of infected plants between production regions several times could have facilitated short bursts of gene flow by M. musicola, with many individuals moving in only one or a few generations. The time frame over which gene flow has occurred cannot be determined from indirect gene flow measures based on allele frequency data. However, populations such as Q2 and N1 may maintain the effects of historical gene flow because of large populations in these major production areas, while populations Q3, Q4, and Q5 may be subject to genetic drift operating more quickly due to small populations.

Host specificity within $M$. musicola was examined by comparing population differentiation between Cavendish and Lady Finger populations sampled from the same plantation. Our preliminary investigation revealed only a $4 \%$ difference between cultivar subpopulations using $F$ statistics $\left(F_{S T}=0.037\right)$ and no evidence was found of host-specific genotypes. The use of larger sample sizes collected from more plants of each cultivar would give a more accurate assessment of genetic differentiation based on host cultivar within the plantation. However, as RFLP markers are assumed to be neutral, pathogenicity tests would also be needed to determine if host-cultivar specificity existed in M. musicola.

The results of this study provide a better understanding of the biology of $M$. musicola in Australia. It has been shown that a moderate level of genetic diversity exists within the populations examined, and that the populations exhibit mixed modes of repro- duction. The importance of asexual reproduction in $M$. musicola in Australia is demonstrated by highly localized distribution of genotypes within populations and the detection of identical genotypes for different sporodochia within a lesion or different lesions on the same plant. The genetic differentiation observed between populations separated tens or hundreds of kilometers indicates migration by ascospores or conidia may be restricted primarily to local areas. Further assessment of $M$. musicola is required to more accurately evaluate the relative importance of both types of reproduction and spore dispersal from the plant to local area scale.

\section{ACKNOWLEDGMENTS}

This work was supported by the Horticultural Research and Development Corporation, the Cooperative Research Centre for Tropical Plant Protection, and the Centre de Coopération International en Recherche Agronomique pour le Développement (CIRAD, France). Many officers of the Queensland Department of Primary Industries and New South Wales Agriculture assisted H. L. Hayden in providing information on plantations for disease collection. We thank K. Grice (QDPI) for providing the samples from Cooktown; the banana growers community for offering cooperation and interest; N. Grünwald for conducting the rarefaction analysis with algorithm <Rarefac.c>; T. H. Wong, S. Whisson, and M. Ekins for providing technical assistance; A. Drenth and B. McDonald for providing guidance throughout this research; and B. J. Howlett for assisting with manuscript revisions.

\section{LITERATURE CITED}

1. Agapow, P. M., and Burt, A. 2001. Indices of multilocus linkage disequilibrium. Mol. Ecol. Notes 1:101-102.

2. Ardales, E. Y., Leung, H., Vera Cruz, C. M., Mew, T. W., Leach, J. E., and Nelson, R. J. 1996. Hierarchical analysis of spatial variation of the rice bacterial blight pathogen across diverse agroecosystems in the Philippines. Phytopathology 86:241-252.

3. Boeger, J. M., Chen, R. S., and McDonald, B. A. 1993. Gene flow between geographic populations of Mycosphaerella graminicola (anamorph Septoria tritici) detected with restriction fragment length polymorphism markers. Phytopathology 83:1148-1154.

4. Borchardt, D. S., Welz, H. G., and Geiger, H. H. 1998. Genetic structure of Setosphaeria turcica populations in tropical and temperate climates. Phytopathology 88:322-329.

5. Brown, A. H. D., Feldman, M. W., and Nevo, E. 1980. Multilocus structure of natural populations of Hordeum spontaneum. Genetics 96:523-536.

6. Calpouzos, L. 1955. Studies on the Sigatoka disease of bananas and its fungal pathogen. Aitkens Gardens Research Laboratory, Cienfuegos, Cuba.

7. Cavalli-Sforza, L. L., and Edwards, A. W. F. 1967. Phylogenic analyses: Models and estimation procedures. Evolution 32:550-570.

8. Chen, R. S., Boeger, J. M., and McDonald, B. A. 1994. Genetic stability in a population of plant pathogenic fungus over time. Mol. Ecol. 3:209-218.

9. Fouré, E. 1982. Les cercosporioses du bananier et leurs traitements. Comportement des variétés. Etude de la sensibilité variétale des bananiers et plantains à Mycosphaerella fijiensis Morelet au Gabon (maladie des raies noires). I. Incubation et évolution de la maladie. Fruits 37:749-771.

10. Gauhl, F. 1994. Epidemiology and Ecology of Black Sigatoka (Mycosphaerella fijiensis Morelet) on Plantain and Banana (Musa spp.) in Costa Rica, Central America. International Network for the Improvement of Banana and Plantain, Montpellier.

11. Grünwald, N. J., Goodwin, S. B., Milgroom, M. G., and Fry, W. E. 2003. Analysis of genotypic diversity data for populations of microorganisms. Phytopathology 93:738-746.

12. Hayden, H. L. 2001. Population genetic studies of Mycosphaerella species infecting Banana. Ph.D. thesis. Botany Department, The University of Queensland, Brisbane.

13. Hayden, H. L., Carlier, J., and Aitken, E. A. B. 2003. Genetic structure of Mycosphaerella fijiensis populations from Australia, Papua New Guinea and the Pacific Islands. Plant Pathol. 52:703-712.

14. Hayden, H. L., Carlier, J., and Aitken, E. A. B. 2003. Population differentiation in the banana leaf spot pathogen Mycosphaerella musicola, examined at a global scale. Plant Pathol. 52:713-719.

15. Holm, S. 1979. A simple sequentially rejective multiple test procedure. Scand. J. Stat. 6:65-70.

16. Keller, S. M., Wolfe, M. S., McDermott, J. M., and McDonald, B. A. 1997. High genetic similarity among populations of Phaeosphaeria nodorum across wheat cultivars and regions of Switzerland. Phytopathology 87:1134-1139. 
17. Kohli, Y., Morrall, R. A. A., Anderson, J. B., and Kohn, L. M. 1992. Local and trans-Canadian clonal distribution of Sclerotinia sclerotiorum on canola. Phytopathology 82:875-880.

18. Leach, R. 1941. Banana leaf spot Mycosphaerella musicola, the perfect stage of Cercospora musae Zimm. Trop. Agric. (Trinidad) 18:91-95.

19. Leach, R. 1946. Banana leaf spot (Mycosphaerella musicola) on the Gros Michel variety in Jamaica. Investigations on the etiology of the disease and the principles of control by spraying. Government Printer, Kingston, Jamaica.

20. McDonald, B. A., and Martinez, J. P. 1990. DNA restriction fragment length polymorphisms among Mycosphaerella graminicola (anamorph Septoria tritici) isolates collected from a single field. Phytopathology 80:1368-1373.

21. McDonald, B. A., Zhan, J., and Burdon, J. J. 1999. Genetic structure of Rhynchosporium secalis in Australia. Phytopathology 89:639-645.

22. Meredith, D. S. 1970. Banana leaf spot disease (Sigatoka) caused by Mycosphaerella musicola Leach. Commonw. Agric. Bureaux, Surrey, England.

23. Milgroom, M. G. 1996. Recombination and the multilocus structure of fungal populations. Annu. Rev. Phytopathol. 34:457-477.

24. Milgroom, M. G., and Lipari, S. E. 1995. Population differentiation in the chestnut blight fungus, Cryphonectria parasitica, in eastern North America. Phytopathology 85:155-160.

25. Nei, M. 1973. Analysis of gene diversity in subdivided populations. Proc. Natl. Acad. Sci. USA 70:3321-3323.

26. Peever, T. L., Salimath, S. S., Su, G., Kaiser, J., and Muehlbauer, F. J. 2004. Historical and contemporary multilocus population structure of Ascochyta rabiei (teleomorph: Didymella rabiei) in the Pacific Northwest of the United States. Mol. Ecol. 13:291-309.

27. Pegg, K. G., Moore, N. Y., and Bentley, S. 1996. Fusarium wilt of banana in Australia: A review. Aust. J. Agric. Res. 47:637-650.
28. Raymond, M., and Rousset, F. 1995. An exact test for population differentiation. Evolution 49:1280-1283.

29. Rice, W. R. 1989. Analyzing tables of statistical tests. Evolution 43:223-225.

30. Rivas, G. G., Zapater, M. F., Abadie, C., and Carlier, J. 2004. Founder effects and stochastic dispersal at the continental scale of the fungal pathogen of bananas Mycosphaerella fijiensis. Mol. Ecol. 13:471-482.

31. Simmonds, J. H. 1928. Diseases of banana in Queensland. Queensl. Agric. J. 30:438-454

32. Stahel, G. 1937. Notes on Cercospora leaf spot of bananas (Cercospora musae). Trop. Agric. (Trinidad) 14:257-264.

33. Stoddart, J. A., and Taylor, J. F. 1988. Genotypic diversity: Estimation and prediction in samples. Genetics 118:705-711.

34. Stover, R. H. 1963. Sexuality and heterothallism in Mycosphaerella musicola. Can. J. Bot. 41:1531-1532.

35. Stover, R. H. 1964. Leaf spot of bananas caused by Mycosphaerella musicola: Factors influencing production of fructifications and ascospores. Phytopathology 54:1320-1326.

36. Stover, R. H. 1968. Leaf spot of bananas caused by Mycosphaerella musicola: Perithecia and sporodochia production in different climates. Trop. Agric. (Trinidad) 45:1-12.

37. Stover, R. H. 1970. Leaf spot of bananas caused by Mycosphaerella musicola: Role of conidia in epidemiology. Phytopathology 60:856-860.

38. Swofford, D. L., and Selander, R. B. 1981. BIOSYS-1: A FORTRAN program for the comprehensive analysis of electrophoretic data in population genetics and systematics. J. Hered. 72:281-283.

39. Weir, B. S., and Cockerham, C. C. 1984. Estimating $F$-statistics for the analysis of population structure. Evolution 38:1358-1370.

40. Wright, S. 1951. The genetical structure of populations. Ann. Eugen. $15: 323-354$

41. Zimmerman, A. 1902. Über einige an tropischen Kulturpflanzen beobachtete pilze. Zentralbl. Parasitenkd. Infectionskr. 2 Abt. 8:219. 